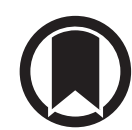

CrossMark

\section{Rationale and significance of patient selection in awake prone positioning for COVID-19 pneumonia}

\author{
To the Editors:
}

We read with interest the research letter by $\mathrm{NG}_{\text {et }}$ al. [1], which described their experience in prone positioning (PP) for awake patients with coronavirus disease 2019 (COVID-19) pneumonia, and concluded that this manoeuvre could delay or reduce the need for intensive care. We agree that the authors demonstrated safety and feasibility of PP in COVID-19 pneumonia patients. However, we humbly suggest a few crucial points be addressed before drawing conclusions on the efficacy of PP.

First, the median time from illness onset to starting oxygen therapy (OT) and awake PP was 9 and 11 days, respectively. In a study reported by Young et al. [2], six out of 18 COVID-19 patients received OT as their oximetry saturations $\left(S_{\mathrm{pO}_{2}}\right)$ were $<92 \%$, and median time from symptom onset to OT initiation was 4 days. Two among these six patients eventually needed intensive care for worsening respiratory failure. However, they had contrasting clinical trajectories, particularly in relation to tempo and extent of deterioration. The first patient desaturated at day 3, with rapid declining oxygenation that necessitated mechanical ventilation by day 8 , while the second only developed hypoxia later at day 10 of illness. Although the latter was admitted to intensive care 3 days later, the patient needed at most venturi mask $50 \%$ and was successfully weaned by day 20 of illness. By referencing local data, it is plausible that most patients in the series reported by $\mathrm{NG}_{\text {et }}$ al. [1] were at low risk of developing severe COVID-19 pneumonia prior to awake PP.

Second, there was considerable patient heterogeneity with regard to severity of hypoxaemia. Unreported information, e.g. chest radiology and protocol to guide PP management, limit data interpretation. COVID-19 pneumonia is increasingly recognised to manifest phenotypic diversity, rather than a strict dichotomy, i.e. phenotype $\mathrm{L}$ and $\mathrm{H}[3,4]$. Moreover, PP's physiological effects would only benefit phenotype $\mathrm{H}$, i.e. typical acute respiratory distress syndrome (ARDS), as characterised by predominantly dorsal consolidation and poor respiratory compliance [4]. Studies on PP in non-intubated ARDS patients pre-dating COVID-19 reported oxygenation improvement but there was no demonstrable improvement in clinical outcomes [5]. There was, however, an increased risk of death attributed to delayed intubation in severe ARDS regardless of choice/combination of adjunct therapies, e.g. noninvasive ventilation/high flow nasal therapy (HFNT) [5, 6].

Third, all but one patient had $S_{\mathrm{pO}_{2}}>90 \%$ on room air at OT initiation. $S_{\mathrm{pO}_{2}} \geqslant 90 \%$ is an American Thoracis Society/Infectious Diseases Society of America 2007 criterion for clinical stability in hospitalised patients with community-acquired pneumonia [7]. Current guidelines do not recommend OT in acute myocardial infarction and stroke patients with $S_{\mathrm{pO}_{2}} 90-92 \%$, as evidence on its potential harm continues to emerge [8]. Similarly, we recommend judicious use of OT, as hyperoxia could exacerbate cytokine release syndrome - the main immunopathological driver implicated in severe coronavirus infections [9]. It is regretful that the study of $\mathrm{NG}_{\text {e }}$ al. [1] did not define indications for OT, which could explain the remarkably discrepant intubation rates (10\% versus $60 \%)$ of COVID-19 pneumonia patients treated at the same centre.

Finally, we would like to share our experience on using awake PP and HFNT (PP+HFNT) in three patients since late April 2020 (table 1). They were managed with the strategy below:

@ERSpublications

COVID-19 is increasingly recognised to manifest phenotypic diversity in clinical presentation, severity and trajectory. As such, treatment, e.g. awake prone positioning, should be personalised and guided by the primary pathophysiology and immunopathology. https://bit.ly/2ZneHlF

Cite this article as: Huang C-F, Tay CK, Zhuang Y-F, et al. Rationale and significance of patient selection in awake prone positioning for COVID-19 pneumonia. Eur Respir J 2020; 56: 2002173 [https://doi.org/ 10.1183/13993003.02173-2020]. 
TABLE 1 Patient characteristics and parameters trends on PP+HFNT

\begin{tabular}{|c|c|c|c|c|c|c|c|c|c|c|c|c|c|c|}
\hline \multicolumn{2}{|l|}{ Patient } & \multicolumn{6}{|c|}{ Patient 1} & \multicolumn{3}{|c|}{ Patient 2} & \multicolumn{4}{|c|}{ Patient 3} \\
\hline \multicolumn{2}{|c|}{$\begin{array}{l}\text { Day of illness at OT initiation }\left(\mathrm{S}_{\mathrm{po}_{2}}\right. \\
<92 \% \text { on room air) }\end{array}$} & \multicolumn{6}{|c|}{7} & \multicolumn{3}{|c|}{5} & \multicolumn{4}{|c|}{3} \\
\hline \multirow[t]{2}{*}{$\begin{array}{l}\text { At PP+HFNT } \\
\text { initiation }\end{array}$} & $\begin{array}{l}\text { Days of } \mathrm{O}_{2} \text { received } \\
\text { (cumulative) }\end{array}$ & 7 & & & & & & \multicolumn{3}{|l|}{12} & \multicolumn{4}{|l|}{2} \\
\hline & PF ratio & 84.8 & & & & & & \multicolumn{3}{|l|}{160} & \multicolumn{4}{|l|}{60.6} \\
\hline Oxygen & $\mathrm{O}_{2}$ devices & HFNT & HFNT & HFNT & HFNT & HFNT & $\mathrm{iNO}_{2}$ & HFNT & HFNT & VM & HFNT & HFNT & HFNT & HFNT \\
\hline \multirow[t]{2}{*}{ requirement } & $\mathrm{F}_{\mathrm{IO}_{2}} \%$ & 100 & 40 & 70 & 40 & 40 & & 40 & 40 & 40 & 50 & 50 & 60 & 100 \\
\hline & Flow L. $\min ^{-1}$ & 60 & 55 & 60 & 50 & 50 & 4 & 55 & 55 & 12 & 50 & 60 & 70 & 70 \\
\hline \multirow{3}{*}{$\begin{array}{l}\text { Respiratory } \\
\text { parameters }\end{array}$} & $\mathrm{S}_{\mathrm{pO}_{2}} \%$ & 100 & 98 & 92 & 93 & 95 & 98 & 93 & 89 & 94 & 94 & 95 & 94 & 90 \\
\hline & PF ratio & 114 & 170 & 77 & & 158 & & 169 & & 165 & 133 & 111 & 91 & 49 \\
\hline & ROX index & 4.2 & 8.8 & 8.2 & 10.1 & 10.3 & 11.3 & 12.9 & 6.5 & 7.8 & 8.5 & 5.2 & 5.5 & 2.9 \\
\hline
\end{tabular}

PP: prone positioning; HFNT: high flow nasal therapy; OT: oxygen therapy; $\mathrm{S}_{\mathrm{pO}_{2}}$ : peripheral oxygen saturation; i $\mathrm{NO}_{2}$ : intranasal oxygen; $\mathrm{VM}$ : Venturi mask; $P_{\mathrm{aO}_{2}}$ : arterial oxygen tension; $F_{\mathrm{IO}_{2}}$ : inspiratory oxygen fraction; $\mathrm{PF}$ ratio: $P_{\mathrm{aO}_{2}} / F_{\mathrm{IO}_{2}}$ ratio; ROX index: ratio of $S_{\mathrm{pO}_{2}} / F_{\mathrm{IO}_{2}}$ to respiratory rate; Day of illness at OT initiation $\left(\mathrm{S}_{\mathrm{pO}_{2}}<92 \%\right.$ on room air): total days of symptoms onset before receiving supplemental oxygen (date of receiving supplemental oxygen - date of symptoms onset + one day); Day of illness at PP+HFNT initiation: total days of illness before PP+HFNT (date of PP+HFNT initiated - date of illness onset + one day); Days of $\mathrm{O}_{2}$ received at PP+HFNT initiation (cumulative): duration of patient on supplemental oxygen before PP+HFNT (date of PP+HFNT initiated - date of receiving supplemental oxygen + one day).

1) Inclusion criteria

- $S_{\mathrm{pO}_{2}}<92 \%$ on intranasal oxygen $\geqslant 6 \mathrm{~L} \cdot \mathrm{min}^{-1}$ or venturi mask $50 \%$; or PF ratio $<200$

- Considerable bilateral opacities on chest radiograph, i.e. compatible with degree of hypoxaemia

- Respiratory rate $<30$ breaths $\cdot \mathrm{min}^{-1}$

- Not using accessory muscles of respiration, i.e. sternocleidomastoids

- No contraindications to PP, e.g. cervical spine instability, pregnancy

2) Manoeuvre

- Four 2-h sessions of PP daily

3) Termination criteria

- ROX index persistently $<4.88$ despite optimising HFNT and/or worsening clinical status requiring intubation

- Patient's inability to tolerate PP

All three patients required OT to keep $S_{\mathrm{pO}_{2}}>92 \%$ by one week of illness. Patients were at day 13,16 and 8 of illness when PP+HFNT was started. The first two required 5 and 2 days of PP+HFNT while the last was intubated for worsening hypoxaemia after 4 days. Our observations echo those of Young et al. [2]. Just as the importance of personalised mechanical ventilation strategies cannot be overemphasised in COVID-19 ARDS, we maintain that selecting the appropriate patient subgroup for awake PP on OT is equally crucial. While we await more data, we opine that awake PP may work in hypoxic COVID-19 whereby the trajectory in oxygenation deterioration is less precipitous, meaning cytokine release syndrome is more indolent (thus causes ARDS over a longer time span), or already abating (the worst is over). Development of a prognostic model derived from clinical, laboratory and physiological data may predict risk of severe hypoxaemia requiring mechanical ventilation and guide personalised treatment in COVID-19 pneumonia.

Ching-Feng Huang $\oplus^{1}$, Chee Kiang Tay $\oplus^{2}$, Ya-Fang Zhuang ${ }^{1}$, Jiaxuan Liu $\oplus^{2}$ and Duu Wen Sewa ${ }^{2}$

${ }^{1}$ Respiratory Therapy Unit, Singapore General Hospital, Singapore. ${ }^{2}$ Dept of Respiratory and Critical Care Medicine, Singapore General Hospital, Singapore.

Correspondence: Duu Wen Sewa, Medical Intensive Care Unit, Dept of Respiratory and Critical Care Medicine, Singapore General Hospital, 20 College Road, Academia, Level 3, Singapore 169856. E-mail: sewa.duu.wen@singhealth. com.sg

Received: 5 June 2020 | Accepted: 22 June 2020

Conflict of interest: None declared. 


\section{References}

$1 \mathrm{Ng} \mathrm{Z}$, Tay WC, Ho CHB. Awake prone positioning for non-intubated oxygen dependent COVID-19 pneumonia patients. Eur Respir J 2020; 56: 2001198.

2 Young BE, Ong SWX, Kalimuddin S, et al. Singapore 2019 Novel Coronavirus Outbreak Research Team. Epidemiologic features and clinical course of patients infected with SARS-CoV-2 in Singapore. JAMA 2020; 323: 1488-1494.

3 Rello J, Storti E, Belliato M, et al. Clinical phenotypes of SARS-CoV-2: implications for clinicians and researchers. Eur Respir J 2020; 55: 2001028.

4 Gattinoni L, Chiumello D, Caironi P, et al. COVID-19 pneumonia: different respiratory treatments for different phenotypes? Intensive Care Med 2020; 46: 1099-1102.

5 Scaravilli V, Grasselli G, Castagna L, et al. Prone positioning improves oxygenation in spontaneously breathing nonintubated patients with hypoxemic acute respiratory failure: A retrospective study. J Crit Care 2015; 30: $1390-1394$.

6 Ding L, Wang L, Ma W, et al. Efficacy and safety of early prone positioning combined with HFNC or NIV in moderate to severe ARDS: a multi-center prospective cohort study. Crit Care 2020; 24: 28.

7 Mandell LA, Wunderink RG, Anzueto A, et al. Infectious Diseases Society of America, American Thoracic Society. Infectious Diseases Society of America/American Thoracic Society consensus guidelines on the management of community-acquired pneumonia in adults. Clin Infect Dis 2007; 44: Suppl. 2, S27-S72.

8 Siemieniuk RAC, Chu DK, Kim LH-Y, et al. Oxygen therapy for acutely ill medical patients: a clinical practice guideline. BMJ 2018; 363: k4169.

9 Moore JB, June CH. Cytokine release syndrome in severe COVID-19. Science 2020; 368: 473-474.

Copyright (CERS 2020

This version is distributed under the terms of the Creative Commons Attribution Non-Commercial Licence 4.0.

From the authors:

We thank C.F. Huang and co-workers for the points raised regarding our published paper entitled "Awake prone positioning for non-intubated oxygen dependent COVID-19 pneumonia patients" [1].

CrossMark

Our study aimed to provide preliminary data that prone positioning can potentially reduce the need for intensive care in patients with coronavirus disease 2019 (COVID-19) pneumonia. With global teams facing resource depletion in the face of a COVID-19 pandemic, the advent of a low-risk and low-cost manoeuvre could potentially offload our healthcare burden. We left the decision to initiate oxygen therapy and prone positioning in the general ward to the attending clinician. When faced with a hypoxic patient, it would have been ideal, albeit not practical, to wait for phenotypic L or $\mathrm{H}$ observations [2] before deciding on therapy. We agree with C.F. Huang and co-workers that patients with one phenotype may benefit more from awake prone positioning, but our small series was not statistically powered to stratify the differences. In addition, the authors compared our data to the study by Young et al. [3], in which patients were recruited from January to February 2020, i.e. a different time frame from our study.

While bearing in mind that the ROX index is not validated in patients with COVID-19 pneumonia, we recognise the efforts of C.F. Huang and co-workers to explore the effects of prone positioning in various settings, including the use of it in patients who are on high flow nasal cannula therapy.

Awake prone positioning is gaining traction by intensive care societies [4] as an early intervention for patients with COVID-19 pneumonia. We present our experience where awake prone positioning proved to be a logistically easy-to-execute intervention with the potential to reduce intensive care unit workload. We believe that further studies are needed to confirm our results and to evaluate its clinical relevance, which may be addressed with ongoing randomised clinical trials (NCT04347941, NCT04350723).

@ERSpublications

Preliminary evidence suggests that awake prone positioning can be a low-risk, low-cost manoeuvre which can help patients with COVID-19 pneumonia delay or reduce the need for intensive care https:// bit.ly/2OpwHGF

Cite this article as: $\mathrm{Ng} \mathrm{Z}$, Tay WC, Ho CHB. Rationale and significance of patient selection in awake prone positioning for COVID-19 pneumonia. Eur Respir J 2020; 56: 2002571 [https://doi.org/10.1183/ 13993003.02571-2020].

Ziqin Ng $\oplus^{1}$, Woo Chiao Tay $^{2}$ and Choon Heng Benjamin Ho $\oplus^{1}$

${ }^{1}$ Dept of Respiratory and Critical Care Medicine, Tan Tock Seng Hospital, Singapore, Singapore. ${ }^{2}$ Dept of Internal Medicine, Tan Tock Seng Hospital, Singapore, Singapore. 
Correspondence: Ng Ziqin, Dept of Respiratory and Critical Care Medicine, Tan Tock Seng Hospital, 11 Jalan Tan Tock Seng, Singapore 308433. E-mail: ziqin.ng@mohh.com.sg

Received: 30 June 2020 | Accepted: 10 July 2020

Conflict of interest: None declared.

\section{References}

$1 \mathrm{Ng} \mathrm{Z}$, Tay WC, Ho CHB. Awake prone positioning for non-intubated oxygen dependent COVID-19 pneumonia patients. Eur Respir J 2020; 56: 2001198.

2 Gattinoni L, Chiumello D, Caironi P, et al. COVID-19 pneumonia: different respiratory treatments for different phenotypes? Intensive Care Med 2020; 46: 1099-1102.

3 Young BE, Ong SWX, Kalimuddin S, et al. Epidemiologic features and clinical course of patients infected with SARS-CoV-2 in Singapore. JAMA 2020; 323: 1488-1494.

4 Bamford P, Bentley A, Dean J, et al. ICS guidance for prone positioning of the conscious COVID patient 2020. London, Intensive Care Society, 2020. Available from https://emcrit.org/wp-content/uploads/2020/04/2020-04-12Guidance-for-conscious-proning.pdf 